\title{
TESTING FOR ASSEMBLY RULES ALONG DISTURBANCE GRADIENTS IN A RIPARIAN BROADLEAVED FOREST
}

\author{
DYAKOV, N. R. \\ Ecology Department, University of Yambol, 8 Hale, Yambol, Bulgaria \\ (e-mail: nickydyakov@gmail.com) \\ (Received $5^{\text {th }}$ Sep 2018; accepted $12^{\text {th }}$ Nov 2018)
}

\begin{abstract}
Riparian habitats often represent highly disturbed sites with relaxed competitive plant integrations and increased resource supply, which frequently lead to promoted colonization of alien and invasive plant species. Unfortunately, there is a knowledge gap about the assembling mechanisms that govern vegetation structure and composition along disturbance gradients. This study tried to answer the question if riparian vegetation assembling is governed by abiotic or biotic forces, as well as whether the strength and nature of assembling mechanisms change along local disturbance gradients. We used species-based approach in which species data of sampled vegetation were compared with a null model assuming random organization. The resulting variance ratios were regressed on the local flooding and logging disturbance gradients. We found that the studied riparian vegetation is dominated by abiotic assembling rules. Their nature did not change along the two disturbance gradients, but their strength did. It seems that the overwhelming factor that rules the riparian vegetation structure and composition in the area is the periodical flooding from the nearby river. It is most prominent in most frequently flooded habitats, then it slowly decays towards the more distant uplands. Its influence is so powerful that it can overshadow other potential assembling factors, and can promote the establishment of native and exotic (including invasive) species. Perhaps, the biotic filter never plays a significant role in the assembling of this highly disturbed and dynamic vegetation. In order to stop further colonization and to preserve these valuable sites from degradation, additional human-induced disturbances should be completely restricted, and natural ones be kept in its historical range. These findings should not be overlooked in the prospective management activities anymore, but should be incorporated in future action plans. Only then, we can hope that these ecosystems could be conserved at their current state for the upcoming generations.
\end{abstract}

Keywords: riparian forest, niche limitation, biotic filter, habitat filter, null model

\section{Introduction}

Riparian habitats often represent areas governed by disturbance and resource supply gradients (Dyakov and Zhelev, 2013). This often leads to relaxed plant competition (Huston and DeAngelis, 1994; Naeem et al., 2000) and decreased resource uptake, which is eventually followed by colonization of alien plant species (Belote et al., 2008; Brown and Peet, 2003; Davis et al., 2000, 2005; Holle and Simberloff, 2005). Eventual invasion can seriously deteriorate these valuable sites (Richardson et al., 2007). In order to properly conserve riparian habitats, it is urgent for these highly disturbed and prone to degradation ecosystems to be studied, and the relative importance of different assembling mechanisms to be well understood.

There are three main groups of processes known to influence vegetation assembly in a given place (Götzenberger et al., 2012; Weiher and Keddy, 2001). Seed dispersal filter is the first one, governed mainly by stochastic forces, determining which species of the regional species pool will reach the site (Eriksson, 1992; Hubbell, 2001). Then come environmental (habitat) and biotic filters, acting more or less simultaneously, they determine which one of the arrived species will survive and establish (Keddy, 1992). Habitat filter sifts the arrived species based on their physiological adaptations to the local environmental conditions (Weiher et al., 1998). Biotic filter sifts the species based on their 
ecological adaptations to interact with the already established ones (Wilson et al., 1996a). The outcome of these three groups of assembling mechanisms determines the final structure and composition of vegetation. However, the discussion about the relative contribution of each group is far from over and the topic remains essential in vegetation ecology (Götzenberger et al., 2012).

Riparian vegetation is useful model system to study assembling mechanisms because flooding disturbance creates strong environmental gradient that causes species reassembling, and controls establishment and competition among interacting species. It is partly explicable by vegetation propagule pressure that flooding water brings in these habitats, as well as by flood-induced vegetation scouring and sediment deposition (Brown and Peet, 2003). Together with the moisture gradient, running from the riverbed to the upland, it generates diverse vegetation that could not be easily explained by a single assembling mechanism. It is almost completely unclear if dispersal, abiotic or biotic filters dominate community assembling, or how they interact (Fraaije et al., 2015).

Logging tends to shift species composition and increase overall plant diversity (Belote et al., 2012, 2009; Dyakov and Zhelev, 2013). Vegetation resistance (lack or small shift in plant species composition following disturbance) is known to depend on logging intensity, increasing light availability, and the size of regional species pool (Belote et al., 2012), suggesting that the first years after logging disturbance should be most highly dominated by abiotic assembling processes. Then, after 5-10 (or more years), following the site colonization by similar or other species (including exotic and invasive plants) (Dyakov and Zhelev, 2013) from the regional pool, biotic assembling mechanisms should slowly take over and begin to dominate local vegetation structuring (Belote et al., 2012, 2009; Mouquet et al., 2003).

Different methods can be used to test for assembly rules. The classical one is focused on species' taxonomic identity and diversity - species-based approach. An alternative one uses species' functional traits, inferring that they represent species adaptation to the environment - trait-based approach (Götzenberger et al., 2012). Among the species-based approaches there are two varieties that have been used - species co-occurrence and niche limitation. The first method frequently suffers from ambiguities due to not controlling for environmental heterogeneity (Götzenberger et al., 2012), therefore, the second one is often preferred. When employing it, it is better to be based on species abundances (Wilson et al., 1996b), because abundance is highly variable in almost all plant communities and assembling rules may be visible only in species abundance (Weiher and Keddy, 2001; Wilson and Gitay, 1995).

Since the earliest work on community assembly rules, null models were used to simulate random samples employing mathematical algorithm to redistribute the data of the original ones (Götzenberger et al., 2012; Wilson et al., 1987). For example, evidence for niche limitation can be achieved by comparing the observed variation in species richness or diversity to that of random communities (Palmer and van der Maarel, 1995). Lower than expected variance in species richness indicates niche limitation, though not always (Palmer and van der Maarel, 1995), i.e. the vegetation is structured mainly by biotic interactions. Higher than expected variance means that there is higher environmental heterogeneity, i.e. the vegetation is structured mainly by abiotic assembly rules (Götzenberger et al., 2016). However, there is necessity to "discount most of the effects of the environmental heterogeneity", which is often accomplished through application of a patch-based null model (Wilson and Gitay, 1995). 
This study's objective was to determine if biotic or abiotic rules dominate the vegetation assembling, and if the nature and strength of vegetation assembling rules change along the disturbance gradient? If the vegetation assembling is dominated by abiotic rules, then 1) the observed variation of sampled vegetation will be greater than the null model, or 2) lesser than the null model - if it is assembled by biotic rules. If the vegetation assembling rules do not change along the disturbance gradient, 3 ) then variance ratio between observed versus expected species frequency and abundance should be constant along the disturbance gradient. It was assumed that the vegetation assembling rules will be dominated by abiotic processes and their strength and nature will not change along the disturbance gradient.

\section{Materials and methods}

\section{Study site}

The study site is located in the Southeast Bulgaria, Balkan Peninsula and has the following coordinates: $42^{\circ} 13^{\prime} 05^{\prime \prime}-42^{\circ} 11^{\prime} 00^{\prime \prime} \mathrm{N}$ and $26^{\circ} 33^{\prime} 31^{\prime \prime}-26^{\circ} 34^{\prime} 59^{\prime \prime} \mathrm{E}$ (Fig. 1). It is a mixed riparian broadleaved forest growing on the right lowland river plain of Tundzha River. The total area is about 470 ha. It is surrounded all-around with agricultural fields. This forest is one of the last remaining spots of uncut semi-natural (there are several well established alien/invasive plant species) forests in the area.

Soils are alluvial. Mean annual temperature of the soil at $2 \mathrm{~cm}$ depth is $13{ }^{\circ} \mathrm{C}$. Climate is temperate. Winter is mild, followed by relatively warm spring. Summer is hot, and autumn is very dry. Mean annual temperature is $12^{\circ} \mathrm{C}$. Mean annual rainfall is about $550 \mathrm{~mm}$. Mean annual wind velocity is about $2.5 \mathrm{~m} / \mathrm{s}$, mainly from north and northeast direction. Total sunny days annually are around 90 . Growing period continues for about seven months.

Studied riparian forest is periodically flooded during late winter and early spring months. The flooding is a result of the melting snow and spring rainfall. It causes high river waters, which inundate extensive agricultural and forested territories downstream. In some years, the flooding continues for months, turning the riparian forest into swamp. Furthermore, during the last 20 years, different parts of the studied forest were logged periodically with low to moderate intensity (up to about 50\% canopy reduction).

\section{Field sampling}

Sampling design was based on the gradsect approach of Austin and Heyligers (1990). Its advantages are: (1) relatively cheap, (2) highly effective, (3) easy to apply on the field, but requiring experienced workers. The sampling was done in July, 2009. Studied territory was crossed with several transects running from the moistest parts, near the riverbed, to the driest upper lands. The length of different transects was between 500 and $1100 \mathrm{~m}$. Transect starting points were chosen on random basis. Sampling plots were set systematically along transects. Trying to avoid spatial autocorrelation, the minimal distance between the plots was at least $200 \mathrm{~m}$ (Fig. 1). The sampling plot is a 0.1 ha rectangle $-50 \times 20 \mathrm{~m}$ (Fig. 2). Totally, 42 sample plots were set. The middle line of the rectangle is $50 \mathrm{~m}$ long plastic tape. Along the tape, at equal distances of $10 \mathrm{~m}$ to each other, five $1 \mathrm{~m}^{2}$ subplots $-2 \times$ $0.5 \mathrm{~m}$ rectangles were laid. The exact placement of the subplots (whether on the left or right side) was determined randomly. Due to shrub layer thickness in some plots, setting of five subplots was not possible, instead only four were set. 


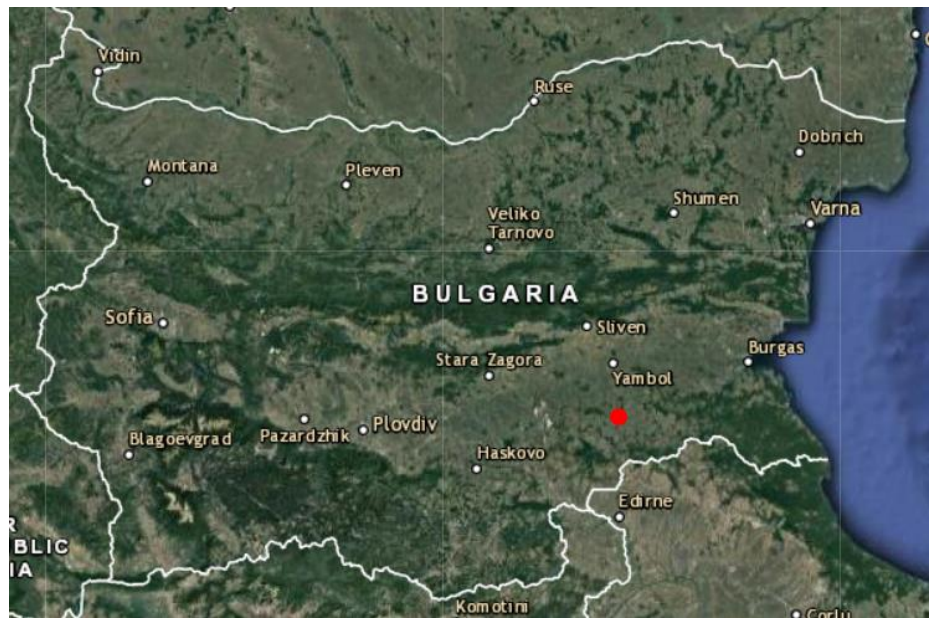

a

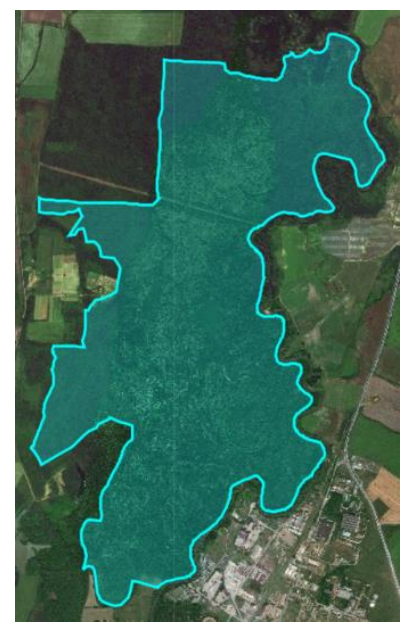

b

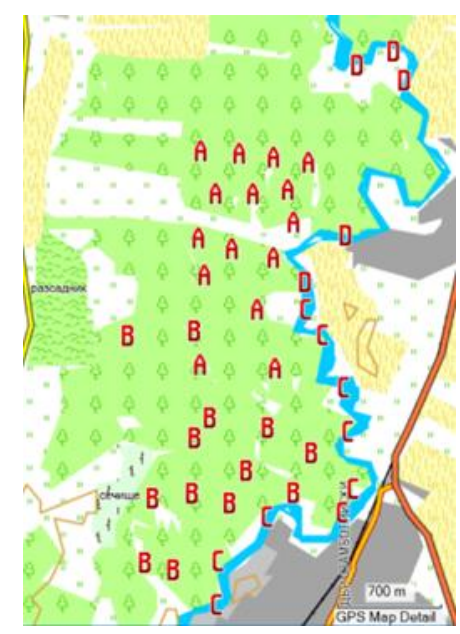

c

Figure 1. a. Overall map of the studied area location depicted as a red dot (above). $\boldsymbol{b}$. Local map with contours of the studied territory (below left). c. Spatial distribution of the 42 sampling plots (below right). $A=$ forest communities dominated by Acer campestre and Crataegus monogyna; $B=$ forest communities dominated by Ulmus minor, Acer campestre and Fraxinus oxycarpa; $C=$ forest communities dominated by Acer negundo and Fraxinus oxycarpa; $D=$ forest communities dominated by Acer negundo (Dyakov and Zhelev, 2013)

As an expression of vegetation abundance in each subplot, species cover was determined visually in percent. Exact distance to the riverbed of all plots was measured on a map. For all samples, years after last logging were calculated using data from forest authority unit. Measured data for total species number, plot cover, tree, shrub, perennial, biennial and annual species number were averaged between the $1 \mathrm{~m}^{2}$ subplots. Trying to express the moisture gradient of habitats and to adapt our sampling design to the patch-based model (Wilson and Gitay, 1995), all 208 subplots were grouped into four Sample Pools (SPs) - beginning with the moistest places (SP1), located nearest to the riverbed, and ending with the driest ones (SP4), located furthermost from the river channel. Dominant plant species in the four SPs were determined on the basis of their mean subplot cover. 


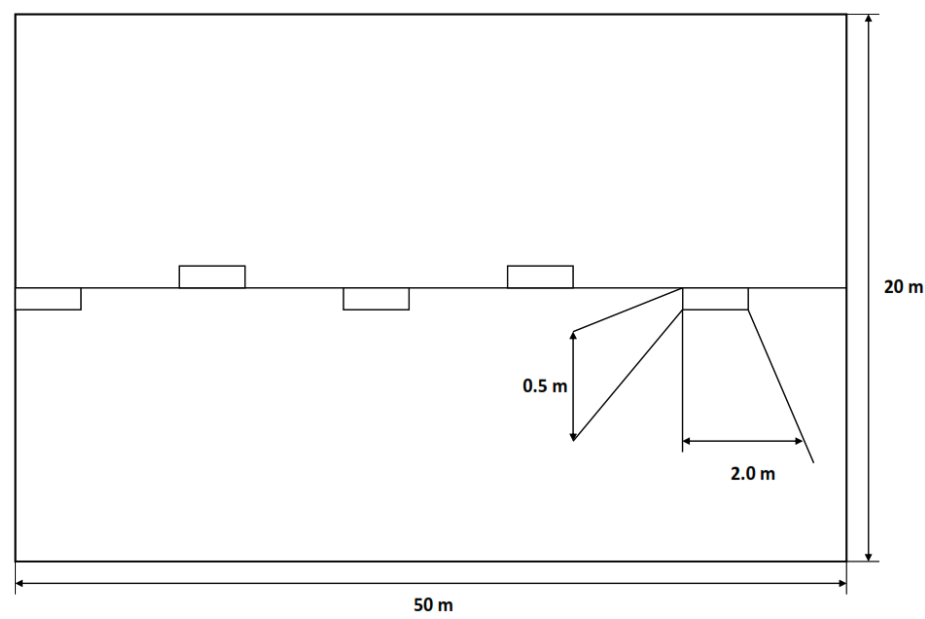

Figure 2. Sampling plot

\section{Statistical analysis}

Before using them, all variables were tested for normality with Shapiro-Wilk test (Shapiro and Wilk, 1965). It is generally preferred method for inquiring if a variable is normally distributed (Zar, 2010). As assumed beforehand, they were not normally distributed, therefore, all sample pools were compared for statistically significant differences in medians with Mood test (Mood, 1954; Zar, 2010). $\beta$-diversity was measured as a DCA (Detrended Correspondence Analysis) (Hill and Gauch, 1980) gradient length in SD (Standard Deviation) units.

\section{Null model}

The test for niche limitation was done using specific randomization for the null model construction. Species $\times$ samples matrix was randomized using the recommended by Götzenberger et al. (2012) "C2" randomization. It randomizes species abundances within samples across all species and keeps fixed species richness and total sample abundance (Götzenberger et al., 2012).

\section{Variance ratios}

We have tracked variance ratio change along the two main disturbance gradients (moisture/flooding gradient, expressed as distance to the riverbed, and logging gradient, expressed as years after logging). Ratios are calculated for the frequency and abundance data separately as a ratio between the observed and expected (null model) variables' variance (Wilson and Gitay, 1995). The two ratios were regressed on the two disturbance gradients and plotted for all species taken together and separated by life forms/guilds (Wilson, 1989). Only trend-lines with maximal $\mathrm{R}^{2}$ [coefficient of determination or explained variation by the fitted regression (Zar, 2010)] values were retained on the graphs.

\section{Results}

The four SPs were compared for differences in the medians for several environmental and vegetation variables shown in Table 1. They were dominated by 
almost identical tree, shrub and herbaceous species. Only SP1 was dominated by a different tree species - Acer negundo - an invasive exotic tree introduced from North America.

Table 1. Comparison of the four SPs by several environmental and vegetation variables

\begin{tabular}{|c|c|c|c|c|}
\hline & $\begin{array}{c}\text { Sample Pool } 1 \\
(n=55)\end{array}$ & $\begin{array}{c}\text { Sample Pool } 2 \\
(n=34)\end{array}$ & $\begin{array}{c}\text { Sample Pool } 3 \\
(n=69)\end{array}$ & $\begin{array}{c}\text { Sample Pool } 4 \\
(n=50)\end{array}$ \\
\hline Distance to riverbed (m) & $\dagger 8(6-23) \mathrm{a}$ & $81(64-142) b$ & $342(294-439) \mathrm{c}$ & $655(604-705) \mathrm{d}$ \\
\hline Years after logging & $17(17-17) \mathrm{a}$ & $12(10-13) b$ & $12(10-12) b$ & $11(10-12) b$ \\
\hline Plot cover $(\%) / 1 \mathrm{~m}^{2}$ & $20(11-37) \mathrm{a}$ & $27(19-34) a$ & $26(18-32) \mathrm{a}$ & $29(20-38) a$ \\
\hline Species number $/ 1 \mathrm{~m}^{2}$ & $4(4-5) a$ & $8(6-9) b$ & $7(7-8) b$ & $9(7-12) b$ \\
\hline $\begin{array}{c}\text { H (Shannon-Weiner } \\
\text { diversity) }\end{array}$ & $\begin{array}{c}0.719 \mathrm{a} \\
(0.582-1.012) \\
\end{array}$ & $\begin{array}{c}1.095 \mathrm{~b} \\
(0.708-1.632) \\
\end{array}$ & $\begin{array}{c}1.215 b c \\
(0.797-1.561) \\
\end{array}$ & $\begin{array}{c}1.552 \mathrm{~d} \\
(1.161-1.825) \\
\end{array}$ \\
\hline$\beta$-diversity & 27.36 & 5.20 & 7.60 & 4.10 \\
\hline E (Evenness) & $\begin{array}{c}0.529 \mathrm{ab} \\
(0.430-0.713)\end{array}$ & $\begin{array}{c}0.613 \mathrm{bc} \\
(0.388-0.733)\end{array}$ & $\begin{array}{c}0.642 \mathrm{c} \\
(0.506-0.720)\end{array}$ & $\begin{array}{c}0.730 \mathrm{~d} \\
(0.642-0.773)\end{array}$ \\
\hline Tree species $/ 1 \mathrm{~m}^{2}$ & $1(1-1) \mathrm{a}$ & $2(1-3) a b$ & $2(1-3) b$ & $3(3-3) b$ \\
\hline Shrub species $/ 1 \mathrm{~m}^{2}$ & $1(1-1) \mathrm{a}$ & $1(1-1) \mathrm{a}$ & $1(0-1) \mathrm{a}$ & $1(0-1) \mathrm{a}$ \\
\hline Perennial species $/ 1 \mathrm{~m}^{2}$ & $2(1-2) a$ & $4(3-4) b$ & $4(3-4) b$ & $5(2-7) b$ \\
\hline $\begin{array}{l}\text { Annual and biennial } \\
\text { species } / 1 \mathrm{~m}^{2}\end{array}$ & $0.0(0.0-0.3) \mathrm{a}$ & $1(0.7-1.0) b$ & $0.8(0.5-0.8) c$ & $0.4(0.2-0.9) \mathrm{abc}$ \\
\hline Alien species $/ 1 \mathrm{~m}^{2}$ & $0.0(0.0-1.0) \mathrm{a}$ & $0.0(0.0-0.0) \mathrm{b}$ & $0.0(0.0-0.0) \mathrm{b}$ & $0.0(0.0-0.0) \mathrm{b}$ \\
\hline Alien cover $/ 1 \mathrm{~m}^{2}$ & $0.0(0.0-0.6) \mathrm{a}$ & $0.0(0.0-0.0) \mathrm{b}$ & $0.0(0.0-0.0) \mathrm{b}$ & $0.0(0.0-0.0) \mathrm{b}$ \\
\hline Dominant trees & Acer negundo & $\begin{array}{c}\text { Ulmus minor } \\
\text { Acer campestre } \\
\text { Quercus robur }\end{array}$ & $\begin{array}{c}\text { Ulmus minor } \\
\text { Acer campestre } \\
\text { Fraxinus oxycarpa }\end{array}$ & $\begin{array}{c}\text { Acer campestre } \\
\text { Fraxinus oxycarpa } \\
\text { Ulmus minor }\end{array}$ \\
\hline Dominant shrubs & Rubus canescens & \begin{tabular}{|} 
Rubus caesius \\
Rubus canescens
\end{tabular} & $\begin{array}{l}\text { Ligustrum vulgare } \\
\text { Rubus canescens }\end{array}$ & $\begin{array}{l}\text { Rubus canescens } \\
\text { Ligustrum vulgare }\end{array}$ \\
\hline Dominant herbs & $\begin{array}{c}\text { Dactylis } \\
\text { glomerata } \\
\text { Myrrhoides } \\
\text { nodosa } \\
\text { Urtica dioica }\end{array}$ & $\begin{array}{c}\text { Chaerophyllum } \\
\text { byzantinum } \\
\text { Chaerophyllum } \\
\text { temulentum } \\
\text { Urtica dioica }\end{array}$ & $\begin{array}{c}\text { Dactylis glomerata } \\
\text { Urtica dioica } \\
\text { Chaerophyllum } \\
\text { temulentum }\end{array}$ & $\begin{array}{c}\text { Chaerophyllum } \\
\text { temulentum } \\
\text { Festuca gigantea } \\
\text { Dactylis glomerata }\end{array}$ \\
\hline
\end{tabular}

${ }^{\dagger}$ Medians (1st-3rd quartile) are shown. Medians in the rows with distinct letters are significantly different at $\mathrm{P} \leq 0.05$ (Mood test)

The four SPs showed significant differences in the distance-to-the-riverbed variable, the annual and biennial species number per $1 \mathrm{~m}^{2}$, as well as in diversity and evenness, especially between SP1 and SP3/SP4. SP1 was also significantly different from the other three pools in perennial species number per $1 \mathrm{~m}^{2}$. However, the change in species diversity and evenness seemed to happen gradually because the intermediate SPs (SP2 and SP3) showed no significant difference between each other. There were no other significant differences among the last three pools in any other variable. However, another variable that attracts attention is $\beta$-diversity length, which is extremely high in the most disturbed SP1. Finally, it should be noticed that SP1 also has significantly higher alien number and cover per $1 \mathrm{~m}^{2}$ compared to the rest three SPs. 


\section{Flooding gradient}

Regression of frequency and abundance variance ratios on flooding gradient is shown in Figure 3.

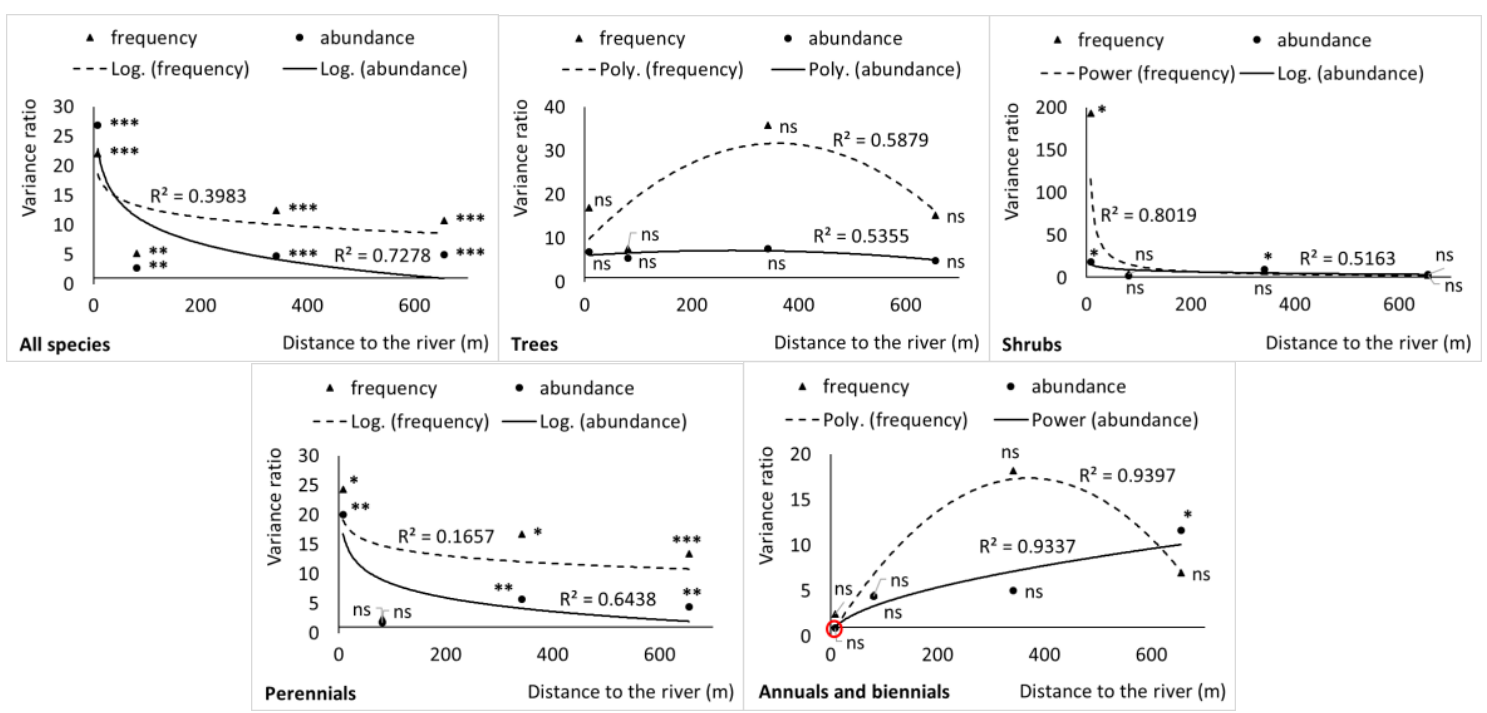

Figure 3. Variance ratio of observed versus expected species frequency and abundance regressed on the distance-to-the-riverbed variable. Only trend-lines with maximal $R^{2}$ were kept. The horizontal unbroken line shows the null model value of variance ratio $=1.0$. The only case where the ratio was below $1.0(0.89)$ is encircled with red circle. The SPs are arranged as in

Table 1. $* P<0.05 ; * * P<0.01 ; * * * P<0.001 ; n s=$ not significant

The prevailing function that best explained ratio variation was logarithmic. In all cases but one, variance ratios were much greater than 1.0, indicating excessive variance among the observed data. Only for abundance data of annuals and biennials in SP1 we have found variance deficit. Yet, it was statistically not significant (Fig. 3). Shrub and perennial species, as well as all species taken together, showed greater variance ratios in the closest to the river habitats (SP1 and SP2), which are also most disturbed. Then, variance ratios gradually declined with the increasing aridity and stability of the environment. Trees, annuals and biennials showed similar trends with maximal ratios in the moderately moist/disturbed habitats, especially for the frequency ratios data.

\section{Logging gradient}

The relationship between variance ratios and logging gradient is shown in Figure 4. Note that data points do not correspond to SPs as they were arranged in Figure 3.

Shrubs, perennials, and all species taken together, showed similar trends for both variance ratios. There is steep increase of ratios with the increasing time after the logging event. The annuals and biennials showed the opposite trend. Trees fall in between, showing hump-shaped trend, especially for the frequency data. However, the overall trend was determined by the perennial life form, likewise in the previous figure too. 


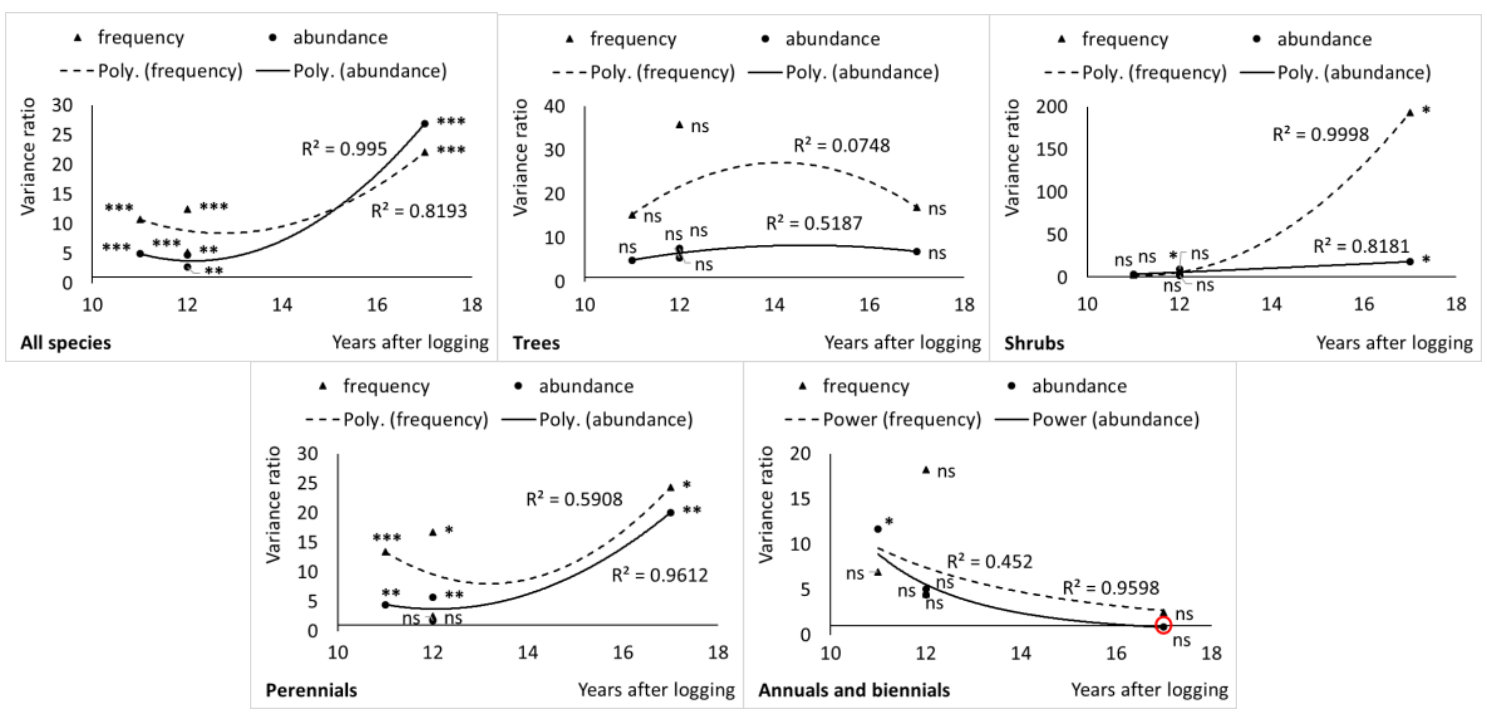

Figure 4. Variance ratio of observed versus expected species frequency and abundance regressed on the years-after-logging variable. Only trend lines with maximal $R^{2}$ were kept. The

horizontal unbroken line shows the null model value of variance ratio $=1.0$. The only case where the ratio was below $1.0(0.89)$ is encircled with red circle. The SPs are not arranged as in Figure 1 and Table 1 (see Table 1 for more details). $* P<0.05 ; * * P<0.01$; *** $P<0.001$; $n s=$ not significant

\section{Discussion}

This study has found that studied riparian vegetation is dominated by abiotic assembly rules. The nature of assembly rules did not change along the two disturbance gradients, but only their strength did. In other words, our results supported the first of the two alternative hypotheses, i.e. that observed variation of sampled vegetation will be greater, compared to the null model. The third tested hypothesis was partly supported too, i.e. that variance ratio of observed versus expected species frequency and abundance will not change along the disturbance gradients.

There is considerable knowledge gap about how disturbance affects assembly rules. It has been suggested, however, that niche-based assembly rules should be weaker in most disturbed communities (Weiher and Keddy, 2001).

\section{Flooding gradient}

This study used a flooding-distance disturbance gradient that runs from the most closely located to the riverbed habitats towards the most distantly located ones, assuming that the former will be most heavily influenced by it (most disturbed), and the later most lightly influenced (least disturbed). Also, trying to overcome habitat heterogeneity, using Wilson and Gitay (1995) patch-based model, all vegetation samples were divided into four sample pools. We found that the most closely located to the riverbed SP1 differs significantly from the other SPs in most vegetation characteristics. For example, species number $/ 1 \mathrm{~m}^{2}$, Shannon diversity, perennial species number $/ 1 \mathrm{~m}^{2}$, and, finally, alien species number and cover $/ 1 \mathrm{~m}^{2}$ distinguish it from the other SPs. However, the more stable habitats had greater native species richness and evenness in contradiction to Cash et al. (2012) (ski-run disturbance). They also had lower $\beta$-diversity in agreement with Myers et al. (2015) (fire disturbance). The opposite 
trend has been documented for the alien species richness, showing highest values in most disturbed places. Aliens like Acer negundo and Amorpha fruticosa, for example, dominated the most frequently disturbed communities, located closely to the river channel. Similar trends, in one aspect, have also been found by Brown and Peet (2003), who reported that riparian habitats were richer on native and exotic species compared to upland areas. They tried to explain this trend with the flooding frequency. In a similar conditions to ours, it was also found (Biswas and Mallik, 2010; Fraaije et al., 2015) that species diversity was maximal at the middle parts of the flooding gradient, sharply decreasing towards the moistest and driest ends. Fraaije et al. (2015) explained this trend with the environmental filter, but also stressed that seed dispersal filter was able to overshadow the environmental filter along the flooding gradient. They suggested that the assembling force of seed dispersal should not be overlooked, especially when studying such highly dynamic communities like riparian vegetation.

Although, in our study, environmental filter dominated along the flooding gradient, its structuring force was greater at the most disturbed sites. Not all functional groups, however, conformed to this trend. For example, the trees and annuals/biennials showed almost entirely nonsignificant variance ratios along the flooding gradient in contradiction to Biswas and Mallik (2010). Hence, observed trend cannot be explained by a single assembling mechanism. Described vegetation composition is probably influenced of several assembling mechanisms (Myers et al., 2015). Predominating role of flooding water is obvious. It not only disturbs the riparian vegetation by its scouring effect (Brown and Peet, 2003; Ward, 1998), but also brings great quantities of sediments (Davis et al., 2000; Tabacchi et al., 1998), as well as numerous propagules (Fraaije et al., 2015; Holle and Simberloff, 2005) from the upstream riverine habitats, including many exotic and invasive species' seeds (Dyakov and Zhelev, 2013; Richardson et al., 2007; Stohlgren et al., 1998). Extremely high measures of $\beta$-diversity in the most disturbed sites probably reflect the compressed habitat breadths (Myers et al., 2015) of many species due to flooding disturbance, hence relaxing biotic filter and enforcing the role of environmental and seed dispersal filters. The outcome is a highly complex system of variously disturbed sites, with different amounts of available soil resources, and varying degrees of native and exotic species colonization.

\section{Logging gradient}

Human-induced disturbance gradient that has been used in the current study is the time-logging gradient. We assumed that the disturbance effect is going to be most severe shortly after logging and will slowly decline with passage of time (Belote et al., 2012). Hence, we expected that the variance ratio of recently logged communities will be much greater than that of earlier-logged ones. However, we did not sample along a real time-logging gradient, but instead we sampled chronosequences, where space replaces time (Christensen and Peet, 1984; Foster and Tilman, 2000), or, with other words, sites with different age since logging were sampled.

What we have found was the opposite of what we expected, i.e. variance ratios increased with passing time since logging, meaning that not only shortly after the logging vegetation assembly was governed by abiotic rules, but also - many (in our case 17) years afterwards. However, there were deviations from this trend. For example, the trees showed maximal ratios 14 years after logging, and the guild of annuals/biennials showed opposite trend - decreasing variance ratios with increasing age since logging. Nevertheless, perennial species had overwhelming role in the general relationship form. 
Although using different approaches, there are previous studies investigating the subject of logging effect on vegetation composition (Belote et al., 2008, 2012, 2009; McDonald et al., 2008; Reiners, 1992). For example, Belote et al. (2012) have found that species diversity decreased after 10 years post-logging at their subplot level, which is equal to our sampling unit of $1 \mathrm{~m}^{2}$, and well agrees with our results for the time interval between 11-th and 20-th year after logging. However, they also found that community resistance - "the ability of a community to maintain compositional integrity" - declined with increasing timber-harvesting disturbance, which was assumed to be minimal shortly after the logging event, and to increase afterwards. High community resistance could be viewed as analogous to low-variance ratio vegetation, which is governed by biotic assembly rules (for instance, competition). In that case, Belote et al. (2012) findings directly contradict what we have found - generally, increasing variance ratio in the post-logging years.

In another study, Belote et al. (2008) investigated diversity-invasibility relationship of Appalachian oak-dominated forests. They found a positive relationship between native and nonnative species across all scales of observation and levels of disturbance, and positive correlation of post-disturbance native and nonnative richness with disturbance intensity. Again, the first part of these finding agrees with our results that communities shortly after disturbance tend to be richer on native species. However, in our case, the least logged communities showed most nonnative richness. A possible explanation could be that the least logged vegetation in our study was located closest to the riverbed, hence, it was also most heavily invaded by alien species. Perhaps, it is due to the propagule pressure (brought by the flooding water), which is most intensive at the closest-to-riverbed habitats (Brown and Peet, 2003), and known to be able to overcome the stressful abiotic conditions (Holle and Simberloff, 2005). It seems that the flooding gradient with its effect is capable to overshadow the other disturbing forces. Another explanation can be sought in a contingent imperfection of riparian vegetation's logging history record, coupled with the drawbacks (Bakker et al., 1996) of chronosequence approach that we used. Still, another explanation could be invoked from other unaccounted disturbance sources, such as wild boar (Sus scrofa) digging activities (which are profound across the area). They were most intensive in the moistest habitats (author pers. observations), bringing additional extensive soil disturbances, and thus, easing exotic species colonization.

\section{Conclusion}

In summary, we have found that the assembling of riparian broadleaved forest under study is governed entirely by abiotic rules. These assembling forces do not change their nature along the local disturbing gradients, but do change only their strength. It seems that the overwhelming factor that rules the riparian vegetation structure and composition is the periodical flooding from nearby river. It is most prominent in most frequently flooded habitats, then slowly decays towards the more distant uplands. Its influence is so powerful that it can overshadow other potential assembling factors, and promote establishment of native and exotic (including invasive) species in the area. Perhaps, biotic filter never plays a significant role in the assembling of this highly disturbed and dynamic vegetation. In order of ceasing further colonization and preserving these valuable sites from degradation, additional human-induced disturbances should be completely restricted, and the natural ones kept in its historical range. These findings 
should not be overlooked in the prospective management activities anymore, but incorporated in future management plans. Only then, we can hope that these ecosystems could be conserved at their current state for the upcoming generations.

Acknowledgements. The author is thankful to Petar Zhelev and Suzana Stankulovska for their help on the field.

\section{REFERENCES}

[1] Austin, M. P., Heyligers, P. (1990): New Approach to Vegetation Survey Design: Gradsect Sampling. - In: Margules, C., Austin, M. (eds.) Nature Conservation: Cost Effective Biological Surveys and Data Analysis. CSIRO, Canberra, Australia, pp. 31-36.

[2] Bakker, J. P., Olff, H., Willems, J. H., Zobel, M. (1996): Why do we need permanent plots in the study of long-term vegetation dynamics? - Journal of Vegetation Science 7: 147-156.

[3] Belote, R. T., Jones, R. H., Hood, S. M., Wender, B. W. (2008): Diversity-invasibility across an experimental disturbance gradient in Appalachian forests. - Ecology 89: 183192.

[4] Belote, R. T., Sanders, N. J., Jones, R. H. (2009): Disturbance alters local-regional richness relationships in Appalachian forests. - Ecology 90: 2940-2947.

[5] Belote, R. T., Jones, R. H., Wieboldt, T. F. (2012): Compositional stability and diversity of vascular plant communities following logging disturbance in Appalachian forests. Ecological Applications 22: 502-516.

[6] Biswas, S. R., Mallik, A. U. (2010): Disturbance effects on species diversity and functional diversity in riparian and upland plant communities. - Ecology 91: 28-35.

[7] Brown, R. L., Peet, R. K. (2003): Diversity and invasibility of southern Appalachian plant communities. - Ecology 84: 32-39.

[8] Cash, F. B., Conn, A., Coutts, S., Stephen, M., Mason, N. W., Anderson, B. J., Wilson, J. B. (2012): Assembly rules operate only in equilibrium communities: Is it true? - Austral Ecology 37: 903-914.

[9] Christensen, N. L., Peet, R. K. (1984): Convergence during secondary forest succession. - Journal of Ecology 72: 25-36.

[10] Davis, M. A., Grime, J. P., Thompson, K. (2000): Fluctuating resources in plant communities: a general theory of invasibility. - Journal of Ecology 88: 528-534.

[11] Davis, M. A., Thompson, K., Philip Grime, J. (2005): Invasibility: the local mechanism driving community assembly and species diversity. - Ecography 28: 696-704.

[12] Dyakov, N., Zhelev, P. (2013): Alien species invasion and diversity of riparian forest according to environmental gradients and disturbance regime. - Applied Ecology and Environmental Research 11: 249-272.

[13] Eriksson, O. (1992): Evolution of seed dispersal and recruitment in clonal plants. - Oikos 63: 439-448.

[14] Foster, B. L., Tilman, D. (2000): Dynamic and static views of succession: testing the descriptive power of the chronosequence approach. - Plant Ecology 146: 1-10.

[15] Fraaije, R. G. A., ter Braak, C. J. F., Verduyn, B., Verhoeven, J. T. A., Soons, M. B. (2015): Dispersal versus environmental filtering in a dynamic system: drivers of vegetation patterns and diversity along stream riparian gradients. - Journal of Ecology 103: 1634-1646.

[16] Götzenberger, L., Botta-Dukát, Z., Lepš, J., Pärtel, M., Zobel, M., de Bello, F. (2016): Which randomizations detect convergence and divergence in trait-based community assembly? A test of commonly used null models. - Journal of Vegetation Science 27: $1275-1287$. 
[17] Götzenberger, L., de Bello, F., Bråthen, K. A., Davison, J., Dubuis, A., Guisan, A., Lepš, J., Lindborg, R., Moora, M., Pärtel, M., Pellissier, L., Pottier, J., Vittoz, P., Zobel, K., Zobel, M. (2012): Ecological assembly rules in plant communities - approaches, patterns and prospects. - Biological Reviews 87: 111-127.

[18] Hill, M. O., Gauch, H. G. (1980): Detrended correspondence analysis: an improved ordination technique. - Vegetatio 42: 47-58.

[19] Holle, B. V., Simberloff, D. (2005): Ecological resistance to biological invasion overwhelmed by propagule pressure. - Ecology 86: 3212-3218.

[20] Hubbell, S. P. (2001): The Unified Neutral Theory of Species Abundance and Diversity. - Princeton University Press, Princeton, NJ.

[21] Huston, M. A., DeAngelis, D. L. (1994): Competition and coexistence: the effects of resource transport and supply rates. - The American Naturalist 144: 954-977.

[22] Keddy, P. A. (1992): Assembly and response rules: two goals for predictive community ecology. - Journal of Vegetation Science 3: 157-164.

[23] McDonald, R. I., Motzkin, G., Foster, D. R. (2008): The effect of logging on vegetation composition in Western Massachusetts. - Forest Ecology and Management 255: 40214031.

[24] Mood, A. M. (1954): On the asymptotic efficiency of certain nonparametric two-sample tests. - The Annals of Mathematical Statistics 25: 514-522.

[25] Mouquet, N., Munguia, P., Kneitel, J., Miller, T. (2003): Community assembly time and the relationship between local and regional species richness. - Oikos 103: 618-626.

[26] Myers, J. A., Chase, J. M., Crandall, R. M., Jiménez, I. (2015): Disturbance alters beta-diversity but not the relative importance of community assembly mechanisms. Journal of Ecology 103: 1291-1299.

[27] Naeem, S., Knops, J. M., Tilman, D., Howe, K. M., Kennedy, T., Gale, S. (2000): Plant diversity increases resistance to invasion in the absence of covarying extrinsic factors. Oikos 91: 97-108.

[28] Palmer, M. W., van der Maarel, E. (1995): Variance in species richness, species association, and niche limitation. - Oikos 203-213.

[29] Reiners, W. A. (1992): Twenty years of ecosystem reorganization following experimental deforestation and regrowth suppression. - Ecological Monographs 62: 503-523.

[30] Richardson, D. M., Holmes, P. M., Esler, K. J., Galatowitsch, S. M., Stromberg, J. C., Kirkman, S. P., Pyšek, P., Hobbs, R. J. (2007): Riparian vegetation: degradation, alien plant invasions, and restoration prospects. - Diversity and Distributions 13: 126-139.

[31] Shapiro, S. S., Wilk, M. B. (1965): An analysis of variance test for normality (complete samples). - Biometrika 52: 591-611.

[32] Stohlgren, T., Bull, K., Otsuki, Y., Villa, C., Lee, M. (1998): Riparian zones as havens for exotic plant species in the central grasslands. - Plant Ecology 138: 113-125.

[33] Tabacchi, E., Correll, D. L., Hauer, R., Pinay, G., Planty-Tabacchi, A.-M., Wissmar, R. C. (1998): Development, maintenance and role of riparian vegetation in the river landscape. - Freshwater Biology 40: 497-516.

[34] Ward, J. V. (1998): Riverine landscapes: biodiversity patterns, disturbance regimes, and aquatic conservation. - Biological Conservation 83: 269-278.

[35] Weiher, E., Keddy, P. (2001): Ecological Assembly Rules: Perspectives, Advances, Retreats - Cambridge University Press, Cambridge.

[36] Weiher, E., Clarke, G. D. P., Keddy, P. A. (1998): Community assembly rules, morphological dispersion, and the coexistence of plant species. - Oikos 81: 309-322.

[37] Wilson, J. B. (1989): A null model of guild proportionality, applied to stratification of a New Zealand temperate rain forest. - Oecologia 80: 263-267.

[38] Wilson, J. B., Gitay, H. (1995): Limitations to species coexistence: evidence for competition from field observations, using a patch model. - Journal of Vegetation Science 6: 369-376. 
[39] Wilson, J. B., Gitay, H., Agnew, A. D. (1987): Does niche limitation exist? - Functional Ecology 391-397.

[40] Wilson, J. B., Crawley, M. J., Dodd, M. E., Silvertown, J. (1996a): Evidence for constraint on species coexistence in vegetation of the Park Grass experiment. - Vegetatio 124: 183-190.

[41] Wilson, J. B., Terry, C. E. W., Trueman, I. C., Jones, G., Atkinson, M. D., Crawley, M. J., Dodd, M. E., Silvertown, J. (1996b): Are there assembly rules for plant species abundance? An investigation in relation to soil resources and successional trends. Journal of Ecology 84: 527-538.

[42] Zar, J. H. (2010): Biostatistical Analysis. - Prentice Hall, Upper Saddle River, NJ. 